\title{
Correction to: The impact of patient advisors on healthcare outcomes: a systematic review
}

\author{
Anjana E. Sharma ${ }^{1 *}$, Margae Knox ${ }^{1}$, Victor L. Mleczko ${ }^{2}$ and J. Nwando Olayiwola ${ }^{3}$
}

\section{Correction}

Following publication of the original article [1], the authors reported that reference no. 4 be changed. The details of the correction are as follows:

Originally, reference 4 was stated as:

Willard-Grace RSA, Parker C, Potter MB. Engaging Patients as Partners in Practice Improvement: A Survey of Community Health Centers. J Clin Outcomes Manag. 2016;23(7):311-9.

The correct reference 4 is:

Willard-Grace, R., Sharma, A.E., Parker C, Potter, M.B. Engaging patients as partners in practice improvement: A survey of community health centers. JCOM. 2016;23(7):311-9.

\begin{abstract}
Author details
'Department of Family and Community Medicine, Center for Excellence in Primary Care, UCSF, 995 Potrero Ave, Ward 83, San Francisco, CA 94110, USA. ${ }^{2}$ Contra Costa Regional Medical Center, Family Medicine Residency Program, 2500 Alhambra Avenue, Martinez, CA 94553, USA. ${ }^{3}$ University of California, San Francisco, 2120 University Avenue, Berkeley, CA 94704, USA.
\end{abstract}

Received: 30 May 2018 Accepted: 1 June 2018

Published online: 11 June 2018

\section{Reference}

1. Sharma AE, et al. The impact of patient advisors on healthcare outcomes: a systematic review. BMC Health Serv Res. 2017;17:693. https://doi.org/10. 1186/s12913-017-2630-4

\footnotetext{
*Correspondence: Anjana.sharma@ucsf.edu

'Department of Family and Community Medicine, Center for Excellence in Primary Care, UCSF, 995 Potrero Ave, Ward 83, San Francisco, CA 94110, USA Full list of author information is available at the end of the article
}

(c) The Author(s). 2018 Open Access This article is distributed under the terms of the Creative Commons Attribution 4.0 International License (http://creativecommons.org/licenses/by/4.0/), which permits unrestricted use, distribution, and reproduction in any medium, provided you give appropriate credit to the original author(s) and the source, provide a link to the Creative Commons license, and indicate if changes were made. The Creative Commons Public Domain Dedication waiver (http://creativecommons.org/publicdomain/zero/1.0/) applies to the data made available in this article, unless otherwise stated. 